Stefano Duga • Giulia Soldà • Rosanna Asselta

Maria Teresa Bonati · Leda Dalprà · Massimo Malcovati

Maria Luisa Tenchini

\title{
Characterization of the genomic structure of the human neuronal nicotinic acetylcholine receptor CHRNA5/A3/B4 gene cluster and identification of novel intragenic polymorphisms
}

Received: May 11, 2001 / Accepted: August 16, 2001

\begin{abstract}
Genes coding for the $\alpha 5, \alpha 3$, and $\beta 4$ subunits (CHRNA5, CHRNA3, and CHRNB4) of the neuronal nicotinic acetylcholine receptors (nAChRs) are clustered on chromosome 15q24. Linkage of this chromosomal region to autosomal dominant nocturnal frontal lobe epilepsy (ADNFLE), an idiopathic partial epilepsy, was reported in one family. Moreover, mutations in other neuronal $\mathrm{nAChR}$ subunit genes coding for the $\alpha 4$ (CHRNA4) and the $\beta 2$ (CHRNB2) subunits were associated with ADNFLE. Apart from the exon-intron structure of $C H R N A 3$, the genomic organization of this gene cluster was unknown, making comprehensive mutational analyses impossible. The genomic structure of CHRNA5 and CHRNB4 is here reported. Moreover, two hitherto unknown introns were identified within the $3^{\prime}$ untranslated region of $C H R N A 3$, causing a partial tail-to-tail overlap with CHRNA5. Four novel intragenic polymorphisms were identified and characterized in the cluster.
\end{abstract}

Key words $C H R N A 5 / A 3 / B 4$ gene cluster • Human neuronal nicotinic acetylcholine receptor (nAChR) . Genomic structure · Tail-to-tail overlap · Autosomal dominant nocturnal frontal lobe epilepsy (ADNFLE) · Polymorphisms.

\section{Introduction}

Neuronal nicotinic acetylcholine receptors (nAChRs) are multisubunit, ligand-gated ion channels expressed in the peripheral and central nervous systems (Clementi et al. 2000). They are formed by different combinations of

S. Duga $\cdot$ G. Soldà $\cdot$ R. Asselta $\cdot$ M.T. Bonati $\cdot$ L. Dalprà ·

M. Malcovati $\cdot$ M.L. Tenchini $(\bowtie)$

Dipartimento di Biologia e Genetica per le Scienze Mediche,

Università di Milano, via Viotti, 3/5-20133 Milano, Italy

Tel. +39-02-58355840; Fax +39-02-58355864

e-mail: MariaLuisa.Tenchini@unimi.it homologous subunits, assembled as pentameric structures giving rise to an aqueous central channel. The receptor subunits are encoded by a gene family composed of at least 12 members classified as $\alpha$ subunits $(\alpha 2$ to $\alpha 10)$ and $\beta$ subunits ( $\beta 2$ to $\beta 4$ ) (Le Novere and Changeux 1995; Lustig et al. 2001). Alpha subunits, characterized by the presence of two adjacent cysteines in their extracellular domain, constitute the major component of the acetylcholine binding site, while $\beta$ subunits have a mainly structural role, although they have been shown to contribute to ligand binding profiles (McGehee 1999). With the exception of $\alpha 7$ and $\alpha 9$ subunits that can assemble into homopentamers, neuronal $\mathrm{nAChRs}$ result from the assembly of five subunits, in a stoichiometry of two $\alpha$ to three $\beta$. The large number of different subunits giving rise to various combinations, including those containing more than one type of $\alpha$ and/or $\beta$ subunit (McGehee 1999), can produce a huge variety of nAChRs, with different biophysical and pharmacological properties. However, the predominant forms are $\alpha 4 \beta 2$ and $\alpha 4 \alpha 5 \beta 2$ in the central nervous system and $\alpha 3 \beta 4$ or $\alpha 3 \alpha 5 \beta 4$ in the peripheral nervous system (McGehee 1999).

Qualitative or quantitative alterations of the nAChRs can cause brain diseases, including idiopathic epilepsies, schizophrenia, Alzheimer disease, and Parkinson disease (Clementi et al. 2000). To date, the pathogenetic mechanism has been elucidated only for autosomal dominant nocturnal frontal lobe epilepsy (ADNFLE, MIM\#600513, MIM*603204, and MIM\#605375), a partial idiopathic epilepsy characterized by clusters of brief nocturnal motor seizures with a frontal lobe semiology (for a review, see Scheffer 2000). Mutations in two members of the nAChR gene family (CHRNA4 and CHRNB2, coding for the $\alpha 4$ and $\beta 2$ subunits, respectively) were demonstrated to be involved in this syndrome (Scheffer and Berkovic 2000; De Fusco et al. 2000; Phillips et al. 2001). All identified mutations affect amino acids that line the aqueous pore within the ion channel structure and determine an alteration of the functional properties of the receptor (De Fusco et al. 2000; Scheffer 2000; Phillips et al. 2001), supporting the concept that idiopathic epilepsies are, at least in part, ion channel disorders. However, mutations in CHRNA4 and CHRNB2 
account only for a small proportion of ADNFLE cases (Tenchini et al. 1999).

Genes for additional subunits of the $\mathrm{nAChR}$ expressed in brain are obvious candidates for mutation in families and sporadic cases, in which no involvement of CHRNA4 or CHRNB2 can be demonstrated by linkage or mutational analyses. In particular, a third locus for ADNFLE was reported on $15 \mathrm{q} 24$, a chromosome region that contains the $C H R N A 5 / A 3 / B 4$ gene cluster coding for the $\alpha 5, \alpha 3$, and $\beta 4$ subunits, respectively. However, neither the gene nor the mutation involved was identified (Phillips et al. 1998).

Although cDNA sequences for $\mathrm{nAChR}$ subunits have been analyzed in humans and in a number of different species, the genomic structure has been described only for CHRNA3, CHRNA4, CHRNA7, CHRNA10, and CHRNB2, coding for the $\alpha 3, \alpha 4, \alpha 7, \alpha 10$, and $\beta 2$ subunits, respectively (Steinlein et al. 1996; Gault et al. 1998; Rempel et al. 1998; Lustig et al. 2001). The overall genomic organization of these genes is conserved and characterized by the presence of six exons, except for $C H R N A 7$, which, both in humans and chick, consists of ten exons as the result of partial gene duplication.

In the present paper, the genomic organization of CHRNA5 and CHRNB4 together with the sequences of exon-intron boundaries are reported. Two novel introns interrupting the $3^{\prime}$ untranslated region (UTR) of $C H R N A 3$ were identified, and $C H R N A 3$ and $C H R N A 5$ were shown to partially overlap at their $3^{\prime}$ ends. Moreover, four novel polymorphisms were identified and their allele frequencies estimated in an Italian population sample.

\section{Subjects and methods}

Sample composition and DNA extraction

Clinical characteristics of analyzed ADNFLE probands were previously described (Oldani et al. 1998; Tenchini et al. 1999). All examined subjects gave informed consent in writing before blood withdrawal. Genomic DNA was extracted from blood samples using the Nucleon BACC1 kit (Amersham Pharmacia Biotech, Uppsala, Sweden). DNAs extracted from normal healthy Italian individuals of both sexes without sleep disorders were used to calculate allele frequencies of the identified polymorphisms.

\section{Long-range polymerase chain reaction}

Long-range inter-exon polymerase chain reaction (PCR) was accomplished using the Expand $20 \mathrm{~kb}$ plus PCR system kit (Roche Diagnostics, Monza, Italy) and a Personal Cycler (Biometra, Göttingen, Germany). Thermal conditions were 10 cycles of $92^{\circ} \mathrm{C}$ for $10 \mathrm{~s}, 60^{\circ}-64^{\circ} \mathrm{C}$ for $30 \mathrm{~s}$, and $68^{\circ} \mathrm{C}$ for 10 $18 \mathrm{~min}$, preceded by $2 \mathrm{~min}$ at $92^{\circ} \mathrm{C}$ and followed by 20 additional cycles with a time increment of $10 \mathrm{~s}$ for each cycle in the elongation step. A final incubation at $68^{\circ} \mathrm{C}$ for $7 \mathrm{~min}$ was also performed.
DNA sequencing

PCRs for the generation of templates were performed on $50-100 \mathrm{ng}$ of genomic DNA in a standard 50 $\mu$ l volume containing $1 \mathrm{x}$ reaction buffer $(10 \mathrm{mM}$ Tris- $\mathrm{HCl}, \mathrm{pH} 8.3,50 \mathrm{mM}$ $\mathrm{KCl}, 0.001 \%$ gelatin), $1.5 \mathrm{mM} \mathrm{MgCl}_{2}, 0.4 \mu \mathrm{M}$ of each primer, $200 \mu \mathrm{M}$ dNTPs, and 2U RED Taq DNA polymerase (Sigma, St. Louis, MO, USA) on a PTC-100 (MJ Research, Watertown, MA, USA) thermal cycler. Thermal conditions were $30-35$ cycles of $95^{\circ} \mathrm{C}$ for $30 \mathrm{~s}, 52^{\circ}-60^{\circ} \mathrm{C}$ for $30 \mathrm{~s}$ and $72^{\circ} \mathrm{C}$ for $20-60 \mathrm{~s}$, preceded by $3 \mathrm{~min}$ at $95^{\circ} \mathrm{C}$ and followed by a final incubation at $72^{\circ} \mathrm{C}$ for $10 \mathrm{~min}$.

Sequencing was performed on both strands, directly on purified PCR products, using the BigDye terminator kit and an automated ABI-310 Genetic Analyzer (Applied Biosystems, Foster City, CA, USA). Factura and Sequence Navigator softwares (Applied Biosystems) were used for mutation detection. Alignments were performed by the BLAST algorithm (http://www.ncbi.nlm.nih.gov/BLAST/).

\section{Primers}

Primers used for inter-exon PCR were designed on the basis of known sequences of the CHRNA5 and CHRNB4 cDNAs (GenBank, accession numbers: NM_000745 and NM_000750) and are listed in Tables 1 and 2, together with primers used for exon amplification and mutational screening of $C H R N A 5$ and $C H R N B 4$. Primers used to amplify CHRNA3 exons were designed on the basis of the known genomic sequences of CHRNA3 (GenBank, accession numbers: AJ007783-AJ007787) and can be provided on request. All primers were from Life Technologies (Inchinnan, Paisley, UK).

Detection of the short tandem repeat (STR) polymorphism

The tetranucleotide-repeat marker identified in intron 2 of CHRNB4 (CHRNB4.IVS2.STR) was amplified using the primer pair B4STR-F (5'-AAAGATCACACCACTGCC CT-3') and 6Fam-B4STR-R (5'-CATCCTATCTGAGAA ATCTTCC-3') in a Personal Cycler (Biometra). Standard $20 \mu \mathrm{l}-\mathrm{PCR}$ reactions contained 50ng genomic DNA, 1x PCR reaction buffer $(20 \mathrm{mM}$ TrisHCl, $\mathrm{pH} 8.4,50 \mathrm{mM} \mathrm{KCl})$, $1.5 \mathrm{mM} \mathrm{MgCl}_{2}, 200 \mu \mathrm{M}$ of each dNTP, $0.4 \mu \mathrm{M}$ of each primer, and $0.5 \mathrm{U}$ Platinum Taq DNA polymerase (Life Technologies). The thermal profile consisted of: an initial denaturation step of $95^{\circ} \mathrm{C}$ for 3 min followed by 30 cycles of $95^{\circ} \mathrm{C}$ for $30 \mathrm{~s}, 60^{\circ} \mathrm{C}$ for $30 \mathrm{~s}$, and $72^{\circ} \mathrm{C}$ for $30 \mathrm{~s}$. A final extension of $10 \mathrm{~min}$ at $72^{\circ} \mathrm{C}$ was added after the last cycle. Amplified products were separated using an ABI-310 Genetic Analyzer; allele sizing was performed by Genescan 3.1 software (Applied Biosystems).

Detection of single-nucleotide polymorphisms (SNPs)

Screening for the $\mathrm{T}>\mathrm{C}$ polymorphism identified at position -5 in intron 3 of $C H R N A 3$ (CHRNA3.IVS3. $-5 \mathrm{~T}>\mathrm{C}$ ) was 
Table 1. Primers used to analyze human CHRNA5 ( $\alpha 5$ subunit of the neuronal nicotinic acetylcholine receptor gene)

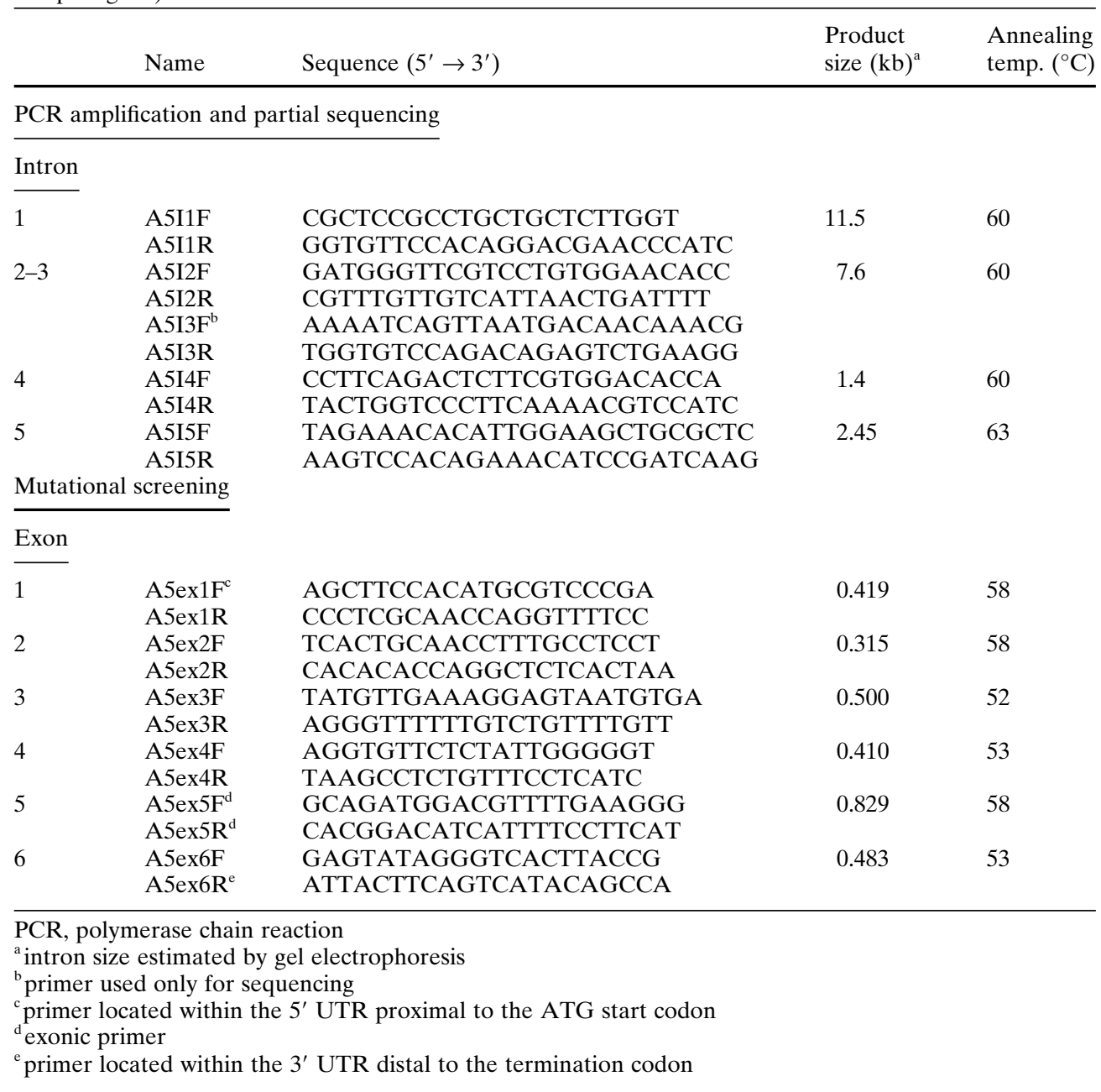

performed by TaqI digestion of PCR products amplified using the following primers: 5'-GGAAGTAAAACCA GGCTGATTC-3' (sense, position 28-49) and 5'-AAGG CCAGGTTTTAAGCACAGT-3' (antisense, position 284-263) (numbering according to CHRNA3 exon 4 sequence, GenBank accession number AJ007785). Digestion products were electrophoresed on $2.5 \%$ agarose gels. CHRNA5.IVS1. $-34 \mathrm{~T}>\mathrm{C}$ and CHRNA5.IVS3. $+211 \mathrm{~A}>\mathrm{G}$ polymorphisms were analyzed by direct sequencing of PCR-amplified genomic DNA.

\section{Results}

CHRNA5 and CHRNB4 genomic structures

The exon-intron organization of CHRNA5 and CHRNB4 was identified by a PCR-based approach. The putative positions of exon-intron junctions were deduced by multiple alignment of several neuronal nAChR subunit genes. Primers were designed taking care to avoid the putative splicing junctions in order to amplify all introns of both genes. Introns 1, 4, and 5 of CHRNA5 and introns 1, 4, and 5 of
CHRNB4 were individually amplified by inter-exon PCR, while introns 2 and 3 were obtained as a single fragment for each gene.

The genomic structure of both genes was defined (Fig. 1), and the sequence of all splicing junctions was obtained by partial sequencing of PCR product ends and by evaluation of fragment lengths by gel electrophoresis. The genomic size was about 25 and $17 \mathrm{~kb}$ for CHRNA5 and CHRNB4, respectively. Both genes are composed of six exons and five introns, in agreement with the overall structure of known nAChR genes. All splice sites in both genes are in accordance with the consensus GT-AG (Shapiro and Senapathy 1987). Nucleotide sequences of CHRNA5 and CHRNB4 have been submitted to the EMBL nucleotide sequence database (accession numbers AJ306481AJ306486 and AJ306454-AJ306459, respectively).

Characterization of a novel tetranucleotide-repeat marker in intron 2 of $C H R N B 4$

Sequencing of $C H R N B 4$ intron 2 revealed the presence of a short tandem repeat (STR) consisting of a tetranucleotide (GAAA) $)_{n}$ repeat, located about $1 \mathrm{~kb}$ upstream of the exon 
Table 2. Primers used to analyze human CHRNB4 ( $\beta 4$ subunit of the neuronal nicotinic acetylcholine receptor gene)

\begin{tabular}{llll} 
& Sequence $\left(5^{\prime} \rightarrow 3^{\prime}\right)$ & $\begin{array}{l}\text { Product } \\
\text { size }(\mathrm{kb})^{\mathrm{a}}\end{array}$ & $\begin{array}{l}\text { Annealing } \\
\text { temp. }\left({ }^{\circ} \mathrm{C}\right)\end{array}$ \\
\hline
\end{tabular}

\begin{tabular}{|c|c|c|c|c|}
\hline \multicolumn{5}{|c|}{ PCR amplification and partial sequencing } \\
\hline \multicolumn{5}{|l|}{ Intron } \\
\hline \multirow[t]{2}{*}{1} & B4I1F & TTCCCTGGTCCTTTTCTTCCTGG & 6 & 60 \\
\hline & B4I1R & TGATGGAGATGAGCTGTGAGGAGC & & \\
\hline \multirow[t]{2}{*}{$2-3$} & B4I2-3F & ACAATAACCTGATCCGCCCAGCC & 4 & 64 \\
\hline & B4I2-3R & GAGCTGTTCCAGGTCAGGCGGTA & & \\
\hline \multirow[t]{2}{*}{4} & B4I4F & CTGACCTGGAACAGCTCCCGCTAC & 1.8 & 63 \\
\hline & B4I4R & AGACACCTCATAGGTCCCGTCGGC & & \\
\hline \multirow[t]{2}{*}{5} & $\mathrm{~B} 4 \mathrm{I} 5 \mathrm{~F}$ & GAAGAATGACGATGAAGACCAGAG & 4 & 60 \\
\hline & B4I5R & CACACAAACATGAACACCCACAG & & \\
\hline \multicolumn{5}{|c|}{ Mutational screening } \\
\hline \multicolumn{5}{|l|}{ Exon } \\
\hline \multirow[t]{2}{*}{1} & $\mathrm{~B} 4 \mathrm{ex} 1 \mathrm{~F}^{\mathrm{b}}$ & GCACGAGCCGCCAGCAAACC & 0.228 & 56 \\
\hline & B4ex1R & CCССТTTCAGCCCAACCCAG & & \\
\hline \multirow[t]{2}{*}{2} & $\mathrm{~B} 4 \mathrm{ex} 2 \mathrm{~F}$ & TCAGGTGCACAAGGGCCCAG & 0.278 & 60 \\
\hline & $\mathrm{B} 4 \mathrm{ex} 2 \mathrm{R}$ & TTCCTTTGACCAATGATCGCCT & & \\
\hline \multirow[t]{2}{*}{3} & $\mathrm{~B} 4 \mathrm{ex} 3 \mathrm{~F}$ & GGAGCTCACAGCCTTTTGCAC & 0.280 & 60 \\
\hline & $\mathrm{B} 4 \mathrm{ex} 3 \mathrm{R}$ & TTGCAGGTCCACTGCCACCAA & & \\
\hline \multirow[t]{2}{*}{4} & $\mathrm{~B} 4 \mathrm{ex} 4 \mathrm{~F}$ & TGGTGGCAGTGGACCTGCAA & 0.250 & 60 \\
\hline & B4ex4R & GGATGACTCTTAGGGCTGGG & & \\
\hline \multirow[t]{4}{*}{5} & $\mathrm{~B} 4 \mathrm{ex} 5 \mathrm{~F} 1^{\mathrm{c}}$ & CGACGGGACCTATGAGGTGT & 0.976 & 58 \\
\hline & $\mathrm{B} 4 \mathrm{ex} 5 \mathrm{R} 1^{\mathrm{c}}$ & ACTCTGGTCTTCATCGTCATTC & & \\
\hline & $\mathrm{B} 4 \mathrm{ex} 5 \mathrm{~F} 2^{\mathrm{d}}$ & TCATCTCCAAGATCGTCGCA & & \\
\hline & $\mathrm{B} 4 \mathrm{ex} 5 \mathrm{R} 2^{\mathrm{d}}$ & CACCATGGTGAACATGAGGT & & \\
\hline \multirow[t]{2}{*}{6} & $\mathrm{~B} 4 \mathrm{ex} 6 \mathrm{~F}$ & GCCCCCCTAGTATGCAGTTC & 0.380 & 60 \\
\hline & $\mathrm{B} 4 \mathrm{ex} 6 \mathrm{R}^{\mathrm{e}}$ & CCACAACCCAGAAAGAAGCAG & & \\
\hline
\end{tabular}

${ }^{a}$ intron size estimated by gel electrophoresis

${ }^{\mathrm{b}}$ primer located within the $5^{\prime}$ UTR proximal to the ATG start codon

${ }^{c}$ exonic primer

${ }^{\mathrm{d}}$ primer used only for sequencing

e primer located within the 3' UTR distal to the termination codon

\section{CHRNA5}

exons

size of exons

size of introns (approx.)

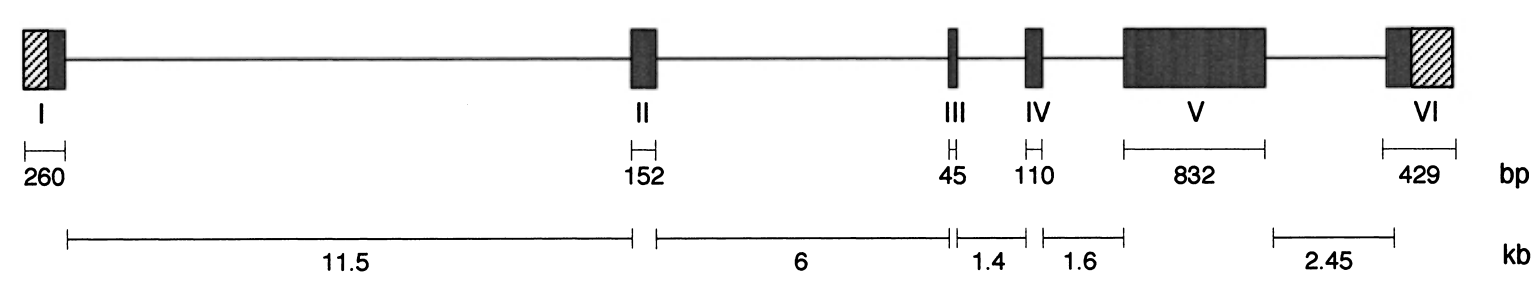

exons
size of exons
size of introns
(approx.)
(approx.)

Fig. 1. Schematic representation of the genomic structure of the $\alpha 5$ and $\beta 4$ subunits of the neuronal nicotinic acetylcholine receptor (CHRNA5 and CHRNB4) genes. Boxes indicate exons; horizontal lines represent introns; hatched boxes indicate the $5^{\prime}$ and the $3^{\prime}$ untranslated regions. Exons and introns are drawn to different scales. The position of the novel tetranucleotide-repeat marker in intron 2 of CHRNB4 is indicated 
Table 3. Allele sizes and frequencies of the novel short tandem repeat market (GAAA) $)_{n}$ identified in intron 2 of $C H R N B 4$

\begin{tabular}{cc}
\hline Allele size (bp) & Allele frequence $(\%)$ \\
\hline 245 & 1.5 \\
249 & 1 \\
253 & 21.5 \\
257 & 43.6 \\
259 & 0.5 \\
261 & 24 \\
265 & 5.9 \\
269 & 0.5 \\
273 & 1 \\
305 & 0.5 \\
\hline
\end{tabular}

3 acceptor splice site. To verify whether this sequence represented a polymorphic site, a primer pair (B4STR-F and 6Fam-B4STR-R) flanking the repeat was designed. The reverse primer was 5'-labeled with 6-Fam. One hundred two unrelated healthy Italian individuals were genotyped by PCR amplification from genomic DNA; PCR products were analyzed using an ABI-310 Genetic Analyzer. A total of ten different alleles were detected, ranging from 245 to $305 \mathrm{bp}$. Allele lengths and frequencies of this novel CHRNB4 marker (CHRNB4.IVS2.STR) are reported in Table 3. Heterozygosity and polymorphism information content (PIC) values are 0.7020 and 0.6549 , respectively.

\section{Mutational analysis}

The search for mutations in the CHRNA5/A3/B4 genes was performed in five unrelated ADNFLE probands. All subjects were chosen from ADNFLE families (nos. 5, 7, 12, 18, and 35) (Oldani et al. 1998; Tenchini et al. 1999) in which segregation analysis excluded linkage to CHRNA4 and CHRNB2 and showed compatibility with linkage to $15 \mathrm{q} 24$ (data not shown). Full sequencing of both strands of exonic regions and exon-intron boundaries of the three genes did not detect any mutation in the analyzed patients.

Single-nucleotide polymorphisms (SNPs) in CHRNA3 and CHRNA5

As a result of sequence analysis of ADNFLE probands, three novel bi-allelic polymorphisms in the CHRNA3 and CHRNA5 genes were detected and designated following the recommendations of Antonarakis (1998). One SNP was identified in intron 3 of CHRNA3 and consisted of a $\mathrm{T}$ to $\mathrm{C}$ transition at nucleotide position -5 (CHRNA3.IVS3. $-5 \mathrm{~T}>\mathrm{C}$ ). This nucleotide variation probably does not alter the corresponding acceptor splice site, since intronic position -5 can be represented by either a C or a T (Shapiro and Senapathy 1987). As this transition abolishes a TaqI restriction site, screening for this polymorphism was performed by PCR amplification of the relevant genomic fragment followed by $T a q \mathrm{I}$ restriction digestion in a control population of 60 unrelated healthy individuals from northern Italy. The remaining two SNPs were
Table 4. Characterization of the three novel SNPs identified in CHRNA3 and CHRNA5

\begin{tabular}{llll}
\hline & $\begin{array}{l}\text { Frequency } \\
\text { of the rare } \\
\text { allele }\end{array}$ & Heterozygosity & PIC \\
\hline CHRP & 0.28 & 0.4032 & 0.3219 \\
CHRNA3.IVS3.-5T $>\mathrm{C}$ & 0.27 & 0.3942 & 0.3165 \\
CHRNA5.IVS3.+211A $>$ G & 0.29 & 0.4118 & 0.3270 \\
\hline
\end{tabular}

SNP, single-nucleotide polymorphism; CHRNA3/A5, $\alpha 3$ and $\alpha 5$ subunits of the neuronal nicotinic acetylcholine receptor gene; PIC, polymorphism information content

identified in CHRNA5 and consisted of a $\mathrm{T}$ to $\mathrm{C}$ transition at position -34 in intron 1 (CHRNA5.IVS1. $-34 \mathrm{~T}>\mathrm{C}$ ) and an $A$ to $G$ transition at position +211 in intron 3 $($ CHRNA5.IVS3. $+211 \mathrm{~A}>\mathrm{G})$. As they did not alter any known restriction site, their frequency was estimated by sequencing genomic DNAs at the relevant positions of the same control individuals as above. The frequencies of the rare allele and the heterozygosity and PIC values of each polymorphism are reported in Table 4.

\section{Identification of two novel CHRNA3 introns}

The previously reported genomic organization of CHRNA3 consisted of six exons and five introns (Rempel et al. 1998). Amplification of exon 6 of this gene for mutational screening with the primer pair A3ex6F (5'-CTGCAACGTGT TGATTACATCTT-3') and A3ex6R (5'-TTCATAGCCC AGGTTCTTGATC- $3^{\prime}$ ) produced a $3.3 \mathrm{~kb}$-fragment, approximately $2.85 \mathrm{~kb}$ larger than that predicted on the basis of the CHRNA3 cDNA sequence. The possible occurrence of intervening sequences was therefore hypothesized. Direct sequencing of this $3.3 \mathrm{~kb}$-fragment and subsequent alignment with the published cDNA of CHRNA3 (Mihovilovic and Roses 1991) demonstrated the presence of two additional introns, located at cDNA positions 1576 and 1674 (numbering from the first nucleotide of the ATG start codon, according to GenBank accession number M37981) (Fig. 2). The newly identified introns 6 and 7 were shown by sequencing to span 2535 and $722 \mathrm{bp}$, respectively, extending $C H R N A 3$ by approximately an additional $3.2 \mathrm{~kb}$ (intron $6+$ intron 7) at its $3^{\prime}$ end. Because the previously described exon 6 turns out to be interrupted by two additional introns, the CHRNA3 exon-intron structure comprises eight exons and seven introns. The presence of an antisense Alu repeat spanning from intron 6 to intron 7 and containing the whole $C H R N A 3$ exon 7 was also identified by BLAST search (Fig. 2).

Tail-to-tail overlap between CHRNA3 and CHRNA5

While the CHRNA3/CHRNB4 intergenic region was shown to span about $4 \mathrm{~kb}$ in humans (Fornasari et al. 1997), the precise distance between the $3^{\prime}$ ends of CHRNA5 and $C H R N A 3$ was unknown. Since we observed that $C H R N A 3$ 


\section{CHRNA3}

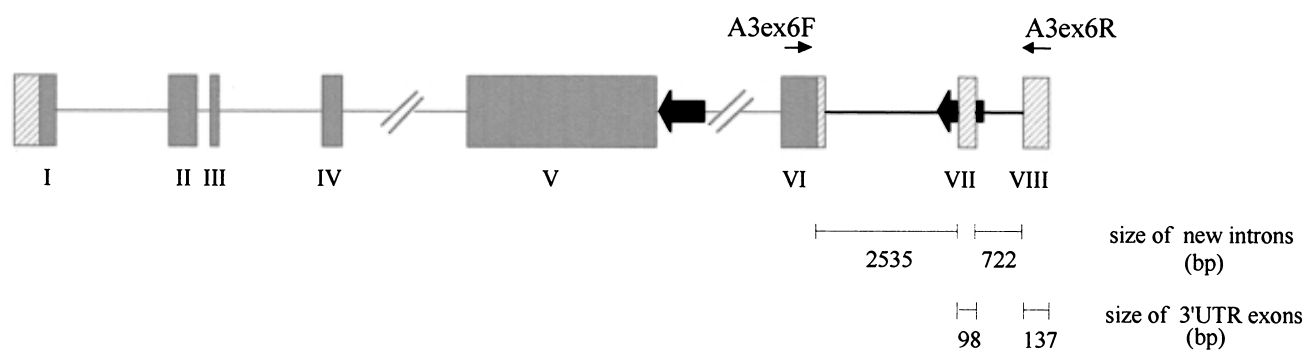

Fig. 2. Genomic structure of the $\alpha 3$ subunit of the neuronal nicotinic acetylcholine receptor gene (CHRNA3) showing the newly identified introns interrupting the $3^{\prime} \mathrm{UTR}$. Boxes indicate exons; horizontal lines represent introns; the 3'UTRs are indicated by hatched boxes. The previously reported region of CHRNA3 (Rempel et al. 1998) is in light gray. Thick arrows represent Alu sequences. A3ex6F and A3ex6R primers used to amplify the $3^{\prime}$ region of $C H R N A 3$ are indicated extends for an additional $3.2 \mathrm{~kb}$ at its $3^{\prime}$ end and $C H R N A 5$ and $C H R N A 3$ were previously reported to be divergently transcribed (Flora et al. 2000a), the existence of a possible overlap between them was explored. To this purpose, an alignment of the $3^{\prime}$ regions of the two genes was performed. This analysis identified an overlapping region of $466 \mathrm{bp}$, corresponding to the whole CHRNA5 exon 6 together with $37 \mathrm{bp}$ of the $3^{\prime}$ end of intron 5 on one strand and to the entire CHRNA3 exon 8 plus 329 bp of intron 7 on the opposite strand. A schematic representation of the CHRNA5 and CHRNA3 $3^{\prime}$ ends together with the sequence of the overlapping region is shown in Fig. 3. In order to confirm the existence of a partial tail-to-tail overlap between CHRNA5 and CHRNA3, a PCR assay on genomic DNA using two sense primers located in the $3^{\prime}$ region of intron 5 of both genes was also performed. A PCR product of the expected size (about $3.3 \mathrm{~kb}$ ) was obtained. The cDNAs of CHRNA5 and CHRNA3 share a $100 \mathrm{bp}$-region (corresponding to amino acids 416-448, including the first nucleotide of codon 449) of CHRNA5 and the part immediately upstream of the polyA signal in the 3'UTR of CHRNA3.

In order to verify whether the genomic arrangement of CHRNA5 and CHRNA3 was conserved in other mammalian species, a PCR reaction on rat genomic DNA using rat-specific sense primers located in exon 6 of both genes was performed. A fragment of about $6 \mathrm{~kb}$ was obtained and partially sequenced at both ends. This analysis showed that the 3'UTRs of the cDNAs of CHRNA5 (1435 bp, GenBank accession number NM_017078) and CHRNA3 (282bp, GenBank accession number L31621) are uninterrupted by introns, demonstrating that the two genes are not overlapped in rats. No complementarity between the two sequences was detected.

\section{Discussion}

In recent years, neuronal $\mathrm{nAChRs}$ have been involved in the pathogenesis of or identified as potential therapeutic targets in several neurological disorders such as idiopathic epilepsies (for a review, see Scheffer and Berkovic 2000), Alzheimer disease (for a review, see James and Nordberg
1995), Parkinson disease (Aubert et al. 1992; Schroder et al. 1995), and schizophrenia (Freedman et al. 1997). In particular, nAChR genes CHRNA4 and CHRNB2 have been reported to be involved in the pathogenesis of ADNFLE (Scheffer and Berkovic 2000; De Fusco et al. 2000; Phillips et al. 2001). Precise information on the genomic organization of human neuronal nAChR subunit genes as well as on the primers and conditions for PCR amplifications from genomic DNA are prerequisites for mutational screenings. Here we report detailed data on the genomic organization of $C H R N A 5 / A 3 / B 4$, clustered on chromosome $15 \mathrm{q} 24$. Only the structure of $C H R N A 3$ was previously reported, although its exact genomic size had not been evaluated (Rempel et al. 1998). The exon-intron structures of CHRNA5 and CHRNB4 were identified and shown to be characterized by the presence of six exons and five introns, as observed for other $\mathrm{nAChR}$ coding genes (e.g., CHRNA4 and CHRNB2) (Steinlein et al. 1996; Rempel et al. 1998). Moreover, partial sequences of the $5^{\prime}$ and $3^{\prime}$ ends of each intron were determined for both genes. During the final stage of this work, a large (about $179.4 \mathrm{~kb}$ ) genomic clone (RP11-335K5) containing the $C H R N A 5 / A 3 / B 4$ cluster was deposited in GenBank (accession number AC067863). It was a draft sequence fragmented in 28 uncomplete and unordered pieces, which were reduced to ten in a very recent revision of the same clone. Alignments of the nucleotide sequences of the CHRNA5 and CHRNB4 intronic regions reported in the present paper with the above mentioned RP11-335K 5 clone revealed a perfect identity. Moreover, three small undetermined regions in AC067863, located in CHRNA5 introns 2 and 5, were resolved by our group as poly-thymidine stretches.

Knowledge of the exon-intron structure as well as of the splicing junctions made it possible to perform a comprehensive mutational screening in five unrelated ADNFLE patients belonging to families for which segregation analysis excluded linkage to $C H R N A 4$ and $C H R N B 2$ and for which no clear exclusion of association to the $15 \mathrm{q} 24$ region could be demonstrated by haplotype analysis. No mutations responsible for ADNFLE were found, indicating that these genes may not be responsible for this syndrome in the analyzed families. Nevertheless, given the genetic heterogeneity of ADNFLE (Oldani et al. 1998; Phillips et al. 1998), a 
Fig. 3A-C. Genomic structure of the CHRNA5/A3/B4 gene cluster showing the tail-to-tail overlap between CHRNA5 and CHRNA3. A Schematic representation of the genomic arrangement of the CHRNA5/A3/ $B 4$ gene cluster. Arrows indicate the direction of transcription. $C E N$, centromere; TEL, telomere. B Exon-intron structure of CHRNA5 and CHRNA3 $3^{\prime}$ regions showing their tail-to-tail overlap. Boxes indicate exons; horizontal lines represent introns; the 3' UTRs are denoted by hatched boxes. Asterisks indicate the stop codons. C Nucleotide and amino acid sequences of CHRNA5 (upper strand, exon 6) and of CHRNA3 (lower strand, exons 6 from residue 452 to exon 8 ). The overlap region comprises 466 bp. Exonic sequences are highlighted in light (CHRNA3) and dark gray (CHRNA5). Intronic sequences are in lowercase letters. Consensus splice sites are underlined. Asterisks indicate the stop codons. IVS, intervening sequence

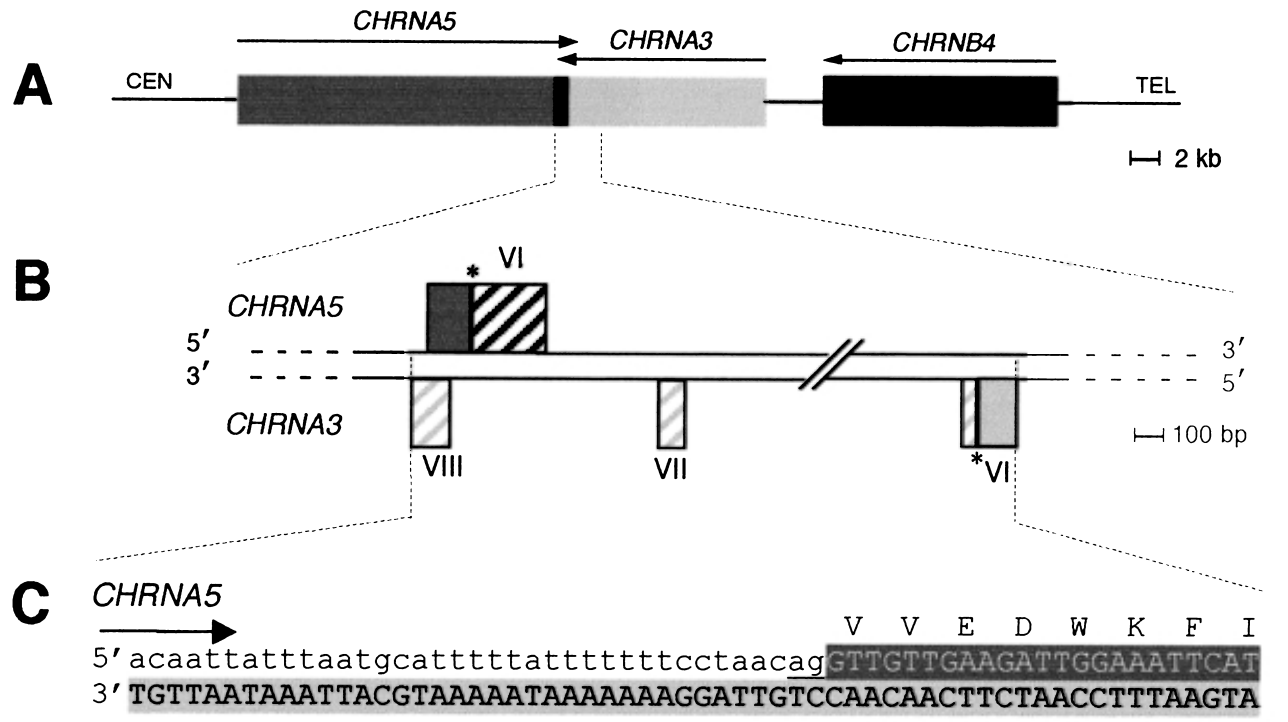

$\begin{array}{llllllllllllllllllllllllllllllllll}A & Q & V & L & D & R & M & F & L & W & T & F & L & F & V & S & I & V & G & S\end{array}$ AGCCCAGGTTCTTGATCGGATGTTTCTGTGGACTTTTCTTTTCGTTTCAATTGTTGGATC TCGGGTCCAAGAACTAGCCTACAAAGACACCTGAAAAGAAAAGCAAAGTTAACAACCTAG

$\begin{array}{lllllllllllllllllllll}L & G & L & F & V & P & V & I & Y & K & W & A & N & I & L & I & P & V & H & I\end{array}$ TCTTGGGCTTTTTGTTCCTGTTATTTATAAATGGGCAAATATATTAATACCAGTTCATAT AGAACCCGAAAAACAAGgacaataatatt tacccgtt tatataattatggtcaagtata G $\quad \mathrm{N} \quad \mathrm{A} \quad \mathrm{N} \quad \mathrm{K} \quad$ *

TGGAAATGCAAATAAGTGAAGCCTCCCAAGGGACT GAAGTATACATTTAGTTAACACACA acctttacgtttattcacttcggagggttccctgacttcatatgtaatcaattgtgtgt TATATCTGATGGCACCTATAAAATTATGAAAATGTAAGTTATGTGTTAAATTAGTGCAA atatagactaccgtggatattttaatacttttacattcaatacacaatttaatcacgtt

GCTTTAACAGACTAAGTTGCTAACCTCAATTTATGTAACAGATGATCCATTTGAACAGT cgaattgtctgattcaacgattggagttaatacaattgtctactaggtaaacttgtca TGGCTGTATGACTGAAGTAATAACTGATGAGATACATTTGATCTTGTAAAAATAGCAAAP accgacatactgacttcattattgactactctatgtaaactagaacatttttatcgtttt

TATTATCTGAACTGGACTAGTGAAAAATCTAGTATTTGTATCCTGG 3' ataatagacttgacctgatcactttttagatcataacataggaccgtttattatg.... .....IVS7.......... accacgtgtgGACATTAGGGTCGATGGACCCTCCGACGCCGTC CTCTTAGCGAACTTGGGTCCACCGCCTCCAACGCCACTCGACTCTAGTGCGGTAACGTGA GGTCGgaccCgttgt........IVS6.......tgcaagaatgATCCTTCGTCGGA GGAGGACGGGACTGTGTTCCTTCAGAGGGTCCGTCCGTGTGTCGAATCACGAATACGTAG * A D

AAGGGACCGGTAGTCCCCAACGTCTTTGTTAGGACGACAGGGATCTTACGTGTGGTCCCA 5' $\begin{array}{llllllllllllllllllll}E & R & A & M & L & P & Q & L & F & L & G & A & T & G & L & I & C & V & L & T\end{array}$ CHRNA3 larger patient cohort should be analyzed in order to exclude these genes as candidates for this disease.

Four novel polymorphisms (three SNPs and one STR) were identified in the $C H R N A 5 / A 3 / B 4$ cluster. All were located in intronic regions. Each clustered gene is marked by at least one polymorphism. Frequencies of the identified polymorphisms were all fairly high with heterozygosity values ranging from 0.3942 to 0.7020 . They therefore represent suitable markers for future association and linkage analyses to these genes.
Amplification of the CHRNA3 3'UTR identified two hitherto unnoticed introns, interrupting the $3^{\prime} \mathrm{UTR}$. CHRNA3 therefore displays a genomic structure (eight exons and seven introns) peculiar among the nAChR gene family. Exon 7 of $C H R N A 3$ is spliced out within an antisense Alu repeat which, on the basis of the nucleotides found at diagnostic positions shared by subfamily members, belongs to the Alu-Sp subfamily (Batzer et al. 1996). It is interesting to note that an antisense Alu repeat located within $C H R N A 3$ intron 5 was previously demonstrated to 
be inserted in the CHRNA3 mRNA by alternative splicing, giving rise to exon 5a (Mihovilovic et al. 1993). This transcriptional variant carries an in-frame stop codon and is expressed at low levels in tissues expressing the normal $\alpha 3$ transcript. An alignment of the newly identified AluSp sequence, located across exon 7 of $C H R N A 3$, with that present in intron 5 of the same gene and belonging to the closely related Alu-Sx subfamily, showed an identity of $77 \%$. Alu elements usually contain several potential splice sites (Ohshima and Gotoh 1987). Comparison of the two transcribed CHRNA3 Alu sequences showed that in both cases the same donor splice site was used, while the acceptor sites were different, the exon 7 acceptor site being 25 nucleotides downstream from that used for the alternative splicing of exon 5 a.

BLAST searches in the human expressed sequence tag (EST) database identified CHRNA3 ESTs lacking exon 7, indicating the occurrence of an alternative splicing of CHRNA3 exon 7.

CHRNA3 and CHRNA5, which are encoded on opposite DNA strands, were shown for the first time to share a 466 bp-region at their $3^{\prime}$ ends. This tail-to-tail overlap produces, at the mRNA level, a $100 \mathrm{bp}$-region of complementarity between CHRNA5 and CHRNA3 mature transcripts. Several pairs of genes are arranged in a similar (tail-to-tail) overlapping manner (Williams and Fried 1986; Tee et al. 1995; Svaren et al. 1997; Quesada et al. 1999; Shintani et al. 1999; Ubeda et al. 1999). For some of these gene couples, such as Stat6/Nab2 (Svaren et al. 1997), CHOP/MetRS (Ubeda et al. 1999), and TC3/T5B (Williams and Fried 1986), the region of overlap is confined to a small region (about 50-100 bp) in the $3^{\prime}$ UTR. This region contains an AUUUA sequence motif (ARE, AU-rich element), which represents a destabilizing sequence involved in the control of mRNA stability (Savant-Bhonsale and Cleveland 1992). It has been suggested that the in vivo formation of RNARNA duplexes involving ARE sequences could increase mRNA stability (Ubeda et al. 1999). Sequence analysis of the $100 \mathrm{bp}$-overlapping region between the CHRNA5 and CHRNA3 mRNAs did not evidence the presence of any ARE sequence motif.

Interestingly, CHRNA3 is partially coexpressed with CHRNA5 in human tissues (Flora et al. 2000b). In the human brain, areas of maximal expression of both subunits were located in the cerebellum and thalamus. In the rat brain, no CHRNA5 expression was detected in the cerebellum, thalamus, and amygdala (Boulter et al. 1990; Wada et al. 1990); moreover, differences in the expression pattern of the $\alpha 3$ subunit between rat and primates have also been reported (Cimino et al. 1992). In this paper, the absence of a gene overlap between CHRNA5 and CHRNA3 in the rat genome was demonstrated. The presence of species-specific differences in the regional expression of neuroreceptors is consistent with the different genomic organization of the CHRNA5/A3/B4 cluster between humans and rats.

Acknowledgments Work was supported by the Italian Telethon Foundation, grant no. E.C. 839. R. A. is a recipient of a Telethon fellowship.

\section{References}

Antonarakis SE (1998) Recommendations for a nomenclature system for human gene mutations. Hum Mutat 11:1-3

Aubert I, Araujo DM, Cecyre D, Robitaille Y, Gauthier S, Quirion R (1992) Comparative alterations of nicotinic and muscarinic binding sites in Alzheimer's and Parkinson's diseases. J Neurochem 58:529541

Batzer MA, Deininger PL, Hellmann-Blumberg U, Jurka J, Labuda D, Rubin CM, Schmid CW, Zietkiewicz E, Zuckerkandl E (1996) Standardized nomenclature for Alu repeats. J Mol Evol 42:3-6

Boulter J, O'Shea-Greenfield A, Duvoisin RM, Connolly JG, Wada E, Jensen A, Gardner PD, Ballivet M, Deneris ES, McKinnon D, Heinemann S, Patrick J (1990) Alpha 3, alpha 5, and beta 4: three members of the rat neuronal nicotinic acetylcholine receptor-related gene family form a gene cluster. J Biol Chem 265:4472-4482

Cimino M, Marini P, Fornasari D, Cattabeni F, Clementi F (1992) Distribution of nicotinic receptors in cynomolgus monkey brain and ganglia: localization of alpha 3 subunit mRNA, alpha-bungarotoxin and nicotine binding sites. Neuroscience 51:77-86

Clementi F, Fornasari D, Gotti C (2000) Neuronal nicotinic receptors, important new players in brain function. Eur J Pharmacol 393:310

De Fusco M, Becchetti A, Patrignani A, Annesi G, Gambardella A, Quattrone A, Ballabio A, Wanke E, Casari G (2000) The nicotinic receptor $\beta 2$ subunit is mutant in nocturnal frontal lobe epilepsy. Nat Genet 26:275-276

Flora A, Schulz R, Benfante R, Battaglioli E, Terzano S, Clementi F, Fornasari D (2000a) Neuronal and extraneuronal expression and regulation of the human alpha5 nicotinic receptor subunit gene. J Neurochem 75:18-27

Flora A, Schulz R, Benfante R, Battaglioli E, Terzano S, Clementi F, Fornasari D (2000b) Transcriptional regulation of the human alpha5 nicotinic receptor subunit gene in neuronal and non-neuronal tissues. Eur J Pharmacol 393:85-95

Fornasari D, Battaglioli E, Flora A, Terzano S, Clementi F (1997) Structural and functional characterization of the human alpha3 nicotinic subunit gene promoter. Mol Pharmacol 51:250-261

Freedman R, Coon H, Myles-Worsley M, Orr-Urtreger A, Olincy A, Davis A, Polymeropoulos M, Holik J, Hopkins J, Hoff M, Rosenthal J, Waldo MC, Reimherr F, Wender P, Yaw J, Young DA, Breese CR, Adams C, Patterson D, Adler LE, Kruglyak L, Leonard S, Byerley W (1997) Linkage of a neurophysiological deficit in schizophrenia to a chromosome 15 locus. Proc Natl Acad Sci U S A 94:587592

Gault J, Robinson M, Berger R, Drebing C, Logel J, Hopkins J, Moore T, Jacobs S, Meriwether J, Choi MJ, Kim EJ, Walton K, Buiting K, Davis A, Breese C, Freedman R, Leonard S (1998) Genomic organization and partial duplication of the human alpha7 neuronal nicotinic acetylcholine receptor gene (CHRNA7). Genomics 52:173185

James JR, Nordberg A (1995) Genetic and environmental aspects of the role of nicotinic receptors in neurodegenerative disorders: emphasis on Alzheimer's disease and Parkinson's disease. Behav Genet 25:149-159

Le Novere N, Changeux JP (1995) Molecular evolution of the nicotinic acetylcholine receptor: an example of multigene family in excitable cells. J Mol Evol 40:155-172

Lustig LR, Peng H, Hiel H, Yamamoto T, Fuchs PA (2001) Molecular cloning and mapping of the human nicotinic acetylcholine receptor alpha10 (CHRNA10). Genomics 73:272-283

McGehee DS (1999) Molecular diversity of neuronal nicotinic acetylcholine receptors. Ann N Y Acad Sci 868:565-577

Mihovilovic M, Roses AD (1991) Expression of mRNAs in human thymus coding for the alpha 3 subunit of a neuronal acetylcholine receptor. Exp Neurol 111:175-180

Mihovilovic M, Mai Y, Herbstreith M, Rubboli F, Tarroni P, Clementi F, Roses A (1993) Splicing of an anti-sense Alu sequence generates a coding sequence variant for the alpha-3 subunit of a neuronal acetylcholine receptor. Biochem Biophys Res Commun 197:137144

Ohshima Y, Gotoh Y (1987) Signals for the selection of a splice site in pre-mRNA. Computer analysis of splice junction sequences and like sequences. J Mol Biol 195:247-250 
Oldani A, Zucconi M, Asselta R, Modugno M, Bonati MT, Dalprà L, Malcovati M, Tenchini ML, Smirne S, Ferini-Strambi L (1998) Autosomal dominant nocturnal frontal lobe epilepsy. A videopolysomnographic and genetic appraisal of 40 patients and delineation of the epileptic syndrome. Brain 121:205-223

Phillips HA, Scheffer IE, Crossland KM, Bhatia KP, Fish DR, Marsden CD, Howell SJ, Stephenson JB, Tolmie J, Plazzi G, EegOlofsson O, Singh R, Lopes-Cendes I, Andermann E, Andermann F, Berkovic SF, Mulley JC (1998) Autosomal dominant nocturnal frontal-lobe epilepsy: genetic heterogeneity and evidence for a second locus at 15q24. Am J Hum Genet 63:1108-1116

Phillips HA, Favre I, Kirkpatrick M, Zuberi SM, Goudie D, Heron SE, Scheffer IE, Sutherland GR, Berkovic SF, Bertrand D, Mulley JC (2001) CHRNB2 is the second acetylcholine receptor subunit associated with autosomal dominant nocturnal frontal lobe epilepsy. Am J Hum Genet 68:225-231

Quesada V, Ponce MR, Micol JL (1999) OTC and AUL1, two convergent and overlapping genes in the nuclear genome of Arabidopsis thaliana. FEBS Lett 461:101-106

Rempel N, Heyers S, Engels H, Sleegers E, Steinlein OK (1998) The structures of the human neuronal nicotinic acetylcholine receptor beta2- and alpha3-subunit genes (CHRNB2 and CHRNA3). Hum Genet 103:645-653

Savant-Bhonsale S, Cleveland DW (1992) Evidence for instability of mRNAs containing AUUUA motifs mediated through translationdependent assembly of a $>20$ S degradation complex. Genes Dev 6:1927-1939

Scheffer IE (2000) Autosomal dominant nocturnal frontal lobe epilepsy. Epilepsia 41:1059-1060

Scheffer IE, Berkovic SF (2000) Genetics of the epilepsies. Curr Opin Pediatr 12:536-542

Schroder H, de Vos RA, Jansen EN, Birtsch C, Wevers A, Lobron C, Nowacki S, Schroder R, Maelicke A (1995) Gene expression of the nicotinic acetylcholine receptor alpha 4 subunit in the frontal cortex in Parkinson's disease patients. Neurosci Lett 187:173-176

Shapiro MB, Senapathy P (1987) RNA splice junctions of different classes of eukaryotes: sequence statistics and functional implications in gene expression. Nucleic Acids Res 15:7155-7174

Shintani S, O'hUigin C, Toyosawa S, Michalova V, Klein J (1999) Origin of gene overlap: the case of TCP1 and ACAT2. Genetics 152:743-754

Steinlein O, Weiland S, Stoodt J, Propping P (1996) Exon-intron structure of the human neuronal nicotinic acetylcholine receptor alpha 4 subunit (CHRNA4). Genomics 32:289-294

Svaren J, Apel ED, Simburger KS, Jenkins NA, Gilbert DJ, Copeland NA, Milbrandt J (1997) The Nab2 and Stat6 genes share a common transcription termination region. Genomics 41:33-39

Tee MK, Thomson AA, Bristow J, Miller WL (1995) Sequences promoting the transcription of the human XA gene overlapping P450c21A correctly predict the presence of a novel, adrenal-specific, truncated form of tenascin-X. Genomics 28:171-178

Tenchini ML, Duga S, Bonati MT, Asselta R, Oldani A, Zucconi M, Malcovati M, Dalprà L, Ferini-Strambi L (1999) SER252PHE and 776INS3 mutations in the CHRNA4 gene are rare in the Italian ADNFLE population. Sleep 22:637-639

Ubeda M, Schmitt-Ney M, Ferrer J, Habener JF (1999) CHOP/ GADD153 and methionyl-tRNA synthetase (MetRS) genes overlap in a conserved region that controls mRNA stability. Biochem Biophys Res Commun 262:31-38

Wada E, McKinnon D, Heinemann S, Patrick J, Swanson LW (1990) The distribution of mRNA encoded by a new member of the neuronal nicotinic acetylcholine receptor gene family (alpha 5) in the rat central nervous system. Brain Res 526:45-53

Williams T, Fried M (1986) A mouse locus at which transcription from both DNA strands produces mRNAs complementary at their $3^{\prime}$ ends. Nature 322:275-279 